the priorities identified is underway and the results will be included in the presentation.

Conclusions A number of robust RPEs examining what is most important for health professionals delivering care to children with LLCs exist. However, more could be done to ensure that the values and experiences of children and young people, their families and other carers are accounted for.

\section{P-87 THE ROLE OF CLINICAL RESEARCH FELLOWS IN THE HOSPICE}

'Alexandra McDougall, 'Sarah Stanley, 'Laura Chapman, ${ }^{2}$ Amara Nwosu. 'Marie Curie Hospice, Liverpool, UK; ${ }^{2}$ Marie Curie Palliative Care Institute Liverpool (MCPCIL), University of Liverpool, Liverpool, UK

10.1136/bmjspcare-2017-hospice.114

Background The need for research is a priority area in palliative care. An evidence based approach is needed to address the inevitable challenges in a population that will require supportive care towards the end of their lives (Gomes \& Higginson, 2008). It is important we continue to develop and evaluate ways of improving the care of people with terminal illness.

Aims Secondment of two local members of staff has allowed our hospice to benefit from an onsite research team. This has given patients, relatives and staff the opportunity to participate in research. We aim to improve care for our patients and hope to provide a foundation for future research projects within the hospice setting.

Method Secondment of staff was achieved using local and national funding, allowing a doctor and nurse to commence the role of clinical research fellow. They were provided with training and mentorship to ensure good understanding of their roles prior to recruitment of patients. A training programme was developed for staff and research update events were instigated, giving staff educational opportunities and freedom to voice their questions and concerns.

Results There is developing evidence which demonstrates that patients are keen to be involved in palliative care research (Henderson et al., 2005; Nwosu et al., 2013), which we have observed with our data collection to date. We hope to build and advance the evidence base.

Conclusion Development of the local research roles provides an excellent foundation to build upon, enabling future research projects to be conducted within the hospice setting. We hope that this will encourage other professionals in palliative care to consider participating in research. We hope researchers, funders and policy makers will be encouraged as participation in research will help to identify, and address, patient-centred priorities at the end-of-life (Nwosu, 2013). Investment in palliative care research is required to generate the evidence which will improve the care delivered to patients at the end-of-life (Sleeman et al., 2012).

\section{P-88 POTENTIAL CHALLENGES FOR NON-NHS ORGANISATIONS CONSIDERING PARTICIPATING IN CLINICAL TRIALS}

Wendy Gamble. LOROS Hospice, Leicester, UK

10.1136/bmispcare-2017-hospice.115
Background Clinical research and participation in clinical trials are still relatively new areas for many hospices and end of life care organisations, particularly if they are non-NHS organisations. One of the more challenging areas of research is that of participation in Clinical Trials of Investigational Medicinal Products (CTIMPS).

Aim The aim of this piece of work is to develop a tool that can be shared with other organisations, both regionally and nationally, to assist them in their preparation for participation in clinical trials.

Methods There are many potential challenges for non-NHS organisations to consider before deciding whether they wish, and are able to, participate safely and effectively in CTIMPS. Although none of these are insurmountable it is important that each aspect is addressed individually to provide the organisation with assurance that the research can be undertaken and delivered safely and to best practice in accordance with regulatory frameworks and guidelines.

The starting point has been to identify the potential challenges. These include but are not limited to:

Infrastructure

Risk and Indemnity

Finance

Governance

Pharmacy

Medicines and Healthcare Regulatory Agency (MHRA)

Drug storage and processes

Training

Tissue samples/storage (HTA)

Monitoring

Sponsor responsibilities.

Results The result of the work thus far is a paper identifying the potential challenges in more detail and the specific issues that require attention.

Conclusions As this is an ongoing project there are no conclusions as yet. The next phase is completion of a RAG rated GAP analysis to identify gaps in current processes, provisions and risks. Once identified, all areas will require careful consideration, associated risks will need to be identified and considered and measures put in place to mitigate these are far as possible.

\section{P-89 THE VOICE OF DYING PEOPLE: LISTENING, LEARNING AND RESPONDING}

Lloyd Riley. Compassion in Dying, London, UK

\subsection{6/bmispcare-2017-hospice.116}

Background We are an organisation that informs and empowers people to exercise their rights at the end of life. 'Personcentred care', 'advance care planning' and 'choice' have become buzzwords in the sector, yet we know from successive policy reports and from people who contact us that in practice these concepts are not always implemented effectively.

Aims To learn more about the experiences of dying people in order to inform our understanding of the barriers to personcentred care.

Methods We designed a mixed-methods exploratory study. This consisted of a questionnaire for dying people and carers, which we distributed via our service-users, social media and other third sector organisations. This received over 600 responses. We also conducted analysis of our service user 